\title{
STUDIES OF THE SHADE REQUIREMENTS OF VANILLA
}

\author{
by \\ Ernesto Hernández Medina \\ Puerto Rico Experiment Station \\ of the \\ U. S. Department of Agriculture \\ Mayagüez, P. R.
}

\section{INTRODUCTION}

The vanilla of commerce [Vanilla fragrans (Salisb.) Ames] requires considerable shade for its best development. In existing vanilleries in Puerto Rico this shade is provided either by the use of the dwarf bucare (Erythrina berteroana Urban), which also serves as a support tree or by existing shade trees such as the guaba (Inga vera Willd.), and the guamá [Inga laurina (Sw.) Willd.]

Newport (5) states that the shade necessary for vanilla is not dense but rather chequered. According to Galbraith (2) in selecting trees for shade those should be chosen which give moderate to about half shade and which do not shed their leaves all at once. Chalot (1) points out the fact that weight and aroma of the beans are greatly influenced by the degree of sunlight to which the vines are exposed. Meinecke (4) states that in general the vanilla vine demands a little more sunlight than shade especially during the flowering season and at the time the beans are maturing. According to McClelland (3) the character of growth of vanilla vines depends greatly on the amount of shade to which the vines are exposed.

- From the literature cited it is evident that some shade is essential for vanilla. Since no record could be found as to the exact amount required, an experiment was conducted at the Puerto Rico Experiment Station to determine this by observing the behavior of the vines when planted uncler different exposures to sunlight. 


\section{EXPERIMENTAL PROCEDURE}

The field used for this experiment had a gentle slope and the soil was a Catalina clay. Drainage ditches in lengthwise and crosswise directions divided the field into 16 contiguous plats each measuring 30 by 20 feet.

The four light exposures tested were as follows: full sunlight, twothirds sunlight, one-half sunlight, and one-third sunlight. Exposures to light less than full were provided by overhead and side bamboo laths appropriately spaced. Each light treatment was replicated 4 times, and there were 30 plants in each replicate making a total of 120 plants per treatment or 480 plants in the entire experiment. Eight-node ranilla cuttings selected for uniform size and vigor were planted at the base of non-living support stakes. The usual mulching practice for vanilla was followed throughout.

All cuttings were planted on October 9 , and every 3 months thereafter data were taken on root formation, seed-piece rotting, and vegetative growth. In addition, the condition of the vines at the termination of the experiment as well as their weights and the number of eight-node cuttings obtained were used to evaluate the various light treatments.

\section{EXPERIMENTAL RESULTS}

\section{Root Formation}

With respect to the number of roots formed, it was found that the vines planted under one-third sunlight consistently produced the greatest

Tab:e 1. Cumulative root formation on vanilla cuttings planted under four exposures to light, Mayagïez, october 9 , 1940.

\begin{tabular}{|c|c|c|c|c|c|}
\hline \multirow{2}{*}{$\begin{array}{c}\text { TreatMent } \\
\text { (Expostre to l.IGHT) }\end{array}$} & \multicolumn{5}{|c|}{ ROO'TS FORMED 1} \\
\hline & $\mathrm{J}_{\mathrm{AN}} \quad 9$ & APRI, 9 & JULY 9 & Oc & $\therefore 9$ \\
\hline & Number & Number & Number & $\mathrm{Nu}$ & IBER \\
\hline Full sunlight _......- & 300 & 293 & 58 & 2 & 53 \\
\hline $2 / 3$ sunlight & 352 & $2 \quad 319$ & $2 \quad 303$ & 2 & 300 \\
\hline $1 / 2$ sunlight & 394 & 410 & 449 & & 472 \\
\hline $1 / 3$ sunlight _........ & 428 & 451 & 498 & 2 & 490 \\
\hline
\end{tabular}

1 On 120 8-node cuttings planted in each treatment.

2 Decrease due to decay of some roots previously formed. 
number of roots, while the vines planted under full sunlight produced the least. The data for root formation are presented in table I.

It is interesting to note that the number of roots formed on the cuttings of each treatment was inversely proportional to the degree of sunlight to which the cuttings were exposed.

\section{Seed-piece Rotting and Stem Growth of Vines}

The data pertaining to seed-piece rotting and stem growth of vines were very interesting. The cuttings grown under one-half and one-third normal sunlight suffered the least amount of stem rotting. In addition, they produced consistently the greatest amount of stem growth. Although the difference between these two treatments was in favor of the vines grown under one-third normal sunlight it was by no means considerable. These results are shown in table II.

As shown in table 2 the vines exposed to full sunlight and two-thirds sunlight sustained the greatest amount of seed-piece rotting and produced the least amount of stem growth. It is clearly seen that the extent of rotting of the seed-pieces was in direct proportion to the degree of sunlight they received, namely, the less the sunlight the lower the percentage of rotting of the seed-pieces. In the case of the stem growth made by the cuttings the reverse was true, that is, the amount of vegetative growth was in inverse proportion to the exposure to light.

Figure 1 shows the cumulative amount of stem growth made by the vines under the different exposures to light at each recorded reading, together with the amount of rainfall measured between readings.

It is evident from figure 1 that at each recorded reading there was no great difference in amount of vegetative growth between the cuttings grown under one-half sunlight and those grown under one-third sunlight. However, there were considerable differences in this respect which were statistically significant between the two treatments of more and less than one-half sunlight. It is of interest to note in figure 1 also that the greatest amount of vegetative growth between readings occurred during periods of abundant rainfall.

\section{Condition of Vines and Weight and Number of Cuttings}

At the termination of the experiment the condition of the vines under the various exposures to light was recorded to determine how the various 


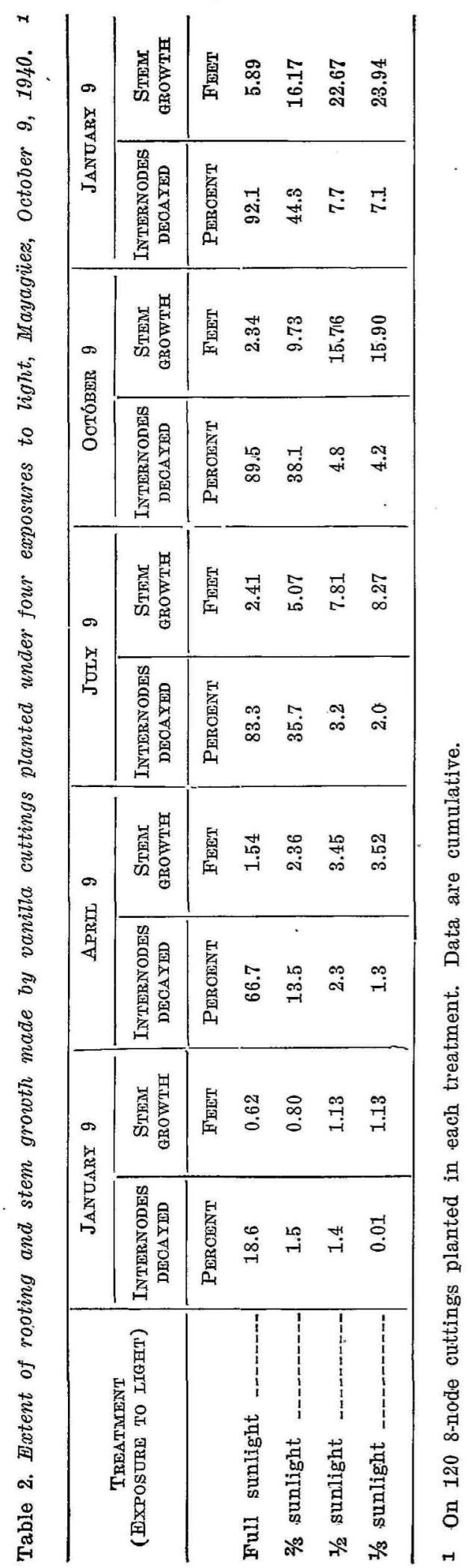




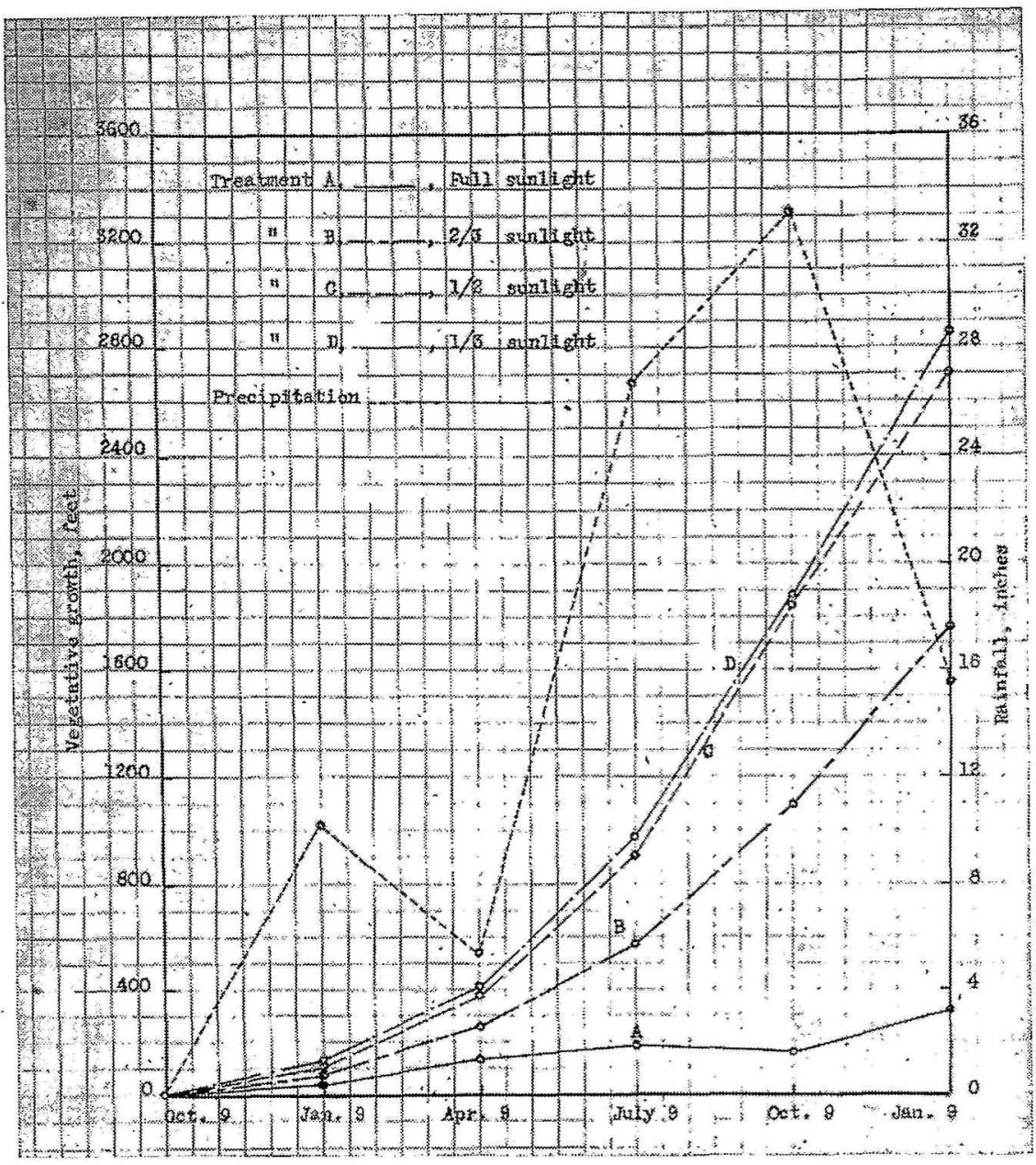

Figure 1. Vegetative growth made by vanilla cuttings at 3-month periods when grown under four exposures to sunlight, together with the amount of rainfall between readings.

degrees of sunlight had affected the development of the vines. This information is summarized in table 3 together with the weight of the vines and number of eight-node cuttings obtained from those grown in each treatment.

The vines grown under one-half and one-third normal sunlight produced the highest percentages of healthy plants and the least percentages 
Table 3. Condition of vanilla plants at end of 15 months planted under four exposures to light, together with weight of vines and number of s-node cuttings per treatment.

\begin{tabular}{|c|c|c|c|c|c|}
\hline \multirow{2}{*}{$\begin{array}{c}\text { TREATMENT } \\
\text { (EXPOSURE TO LIGITT) }\end{array}$} & \multicolumn{3}{|c|}{ CONDITION OF PLANTS } & \multirow{2}{*}{$\begin{array}{l}\text { WEIGHT OF } \\
\text { VINES }\end{array}$} & \multirow{2}{*}{$\begin{array}{l}\text { EIGHT-NONE: } \\
\text { CUTTINGS }\end{array}$} \\
\hline & HeALthy & WILTED & Dead & & \\
\hline & Percent & Percent & Percent & Pounds & NUMBER \\
\hline Full sunlight -- & 32.5 & 16.7 & 50.8 & 26.8 & 142 \\
\hline $2 / 3$ sunlight & 84.2 & 5.0 & 10.8 & 201.0 & 713 \\
\hline $1 / 2$ sunlight & 98.3 & 0.0 & 1.7 & 344.0 & 975 \\
\hline $1 / 3$ sunlight & 96.6 & 1.7 & 1.7 & 366.0 & 963 \\
\hline
\end{tabular}

of wilted and dead plants. The same vines also produced the highest weights and greatest numbers of eight-node cuttings.

The vines grown under full sunlight produced the lowest proportion of healthy plants and highest proportion of wilted and dead plants. It is evident that there were considerable differences in the weights and numbers of eight-node cuttings between the vines exposed to the two lowest exposures to sunlight and those exposed to the two highest degrees of sunlight.

\section{CHARACTER OF GROWTH OF VINES}

Since the beginning of the experiment it was observed that the character of growth of the vines varied with the exposure to light to which they were exposed. The vines exposed to one-third and one-half the normal sunlight developed more vigorously, as illustrated in figure 2 and 3 , than those exposed to two-thirds and full sunlight, as illustrated in figures 4 and 5 . Moreover, the former were of a dark green color and their internodes longer and thicker, as compared to the yellow to yellowish-green and shorter and thinner internodes of the vines exposed to full and two-thirds sunlight.

\section{$S U M M A R Y$}

The work here reported showed that the vanilla plant requires considerable shade for its best development. When vanilla was grown under four exposures to light it was found that the best vine growth from the 


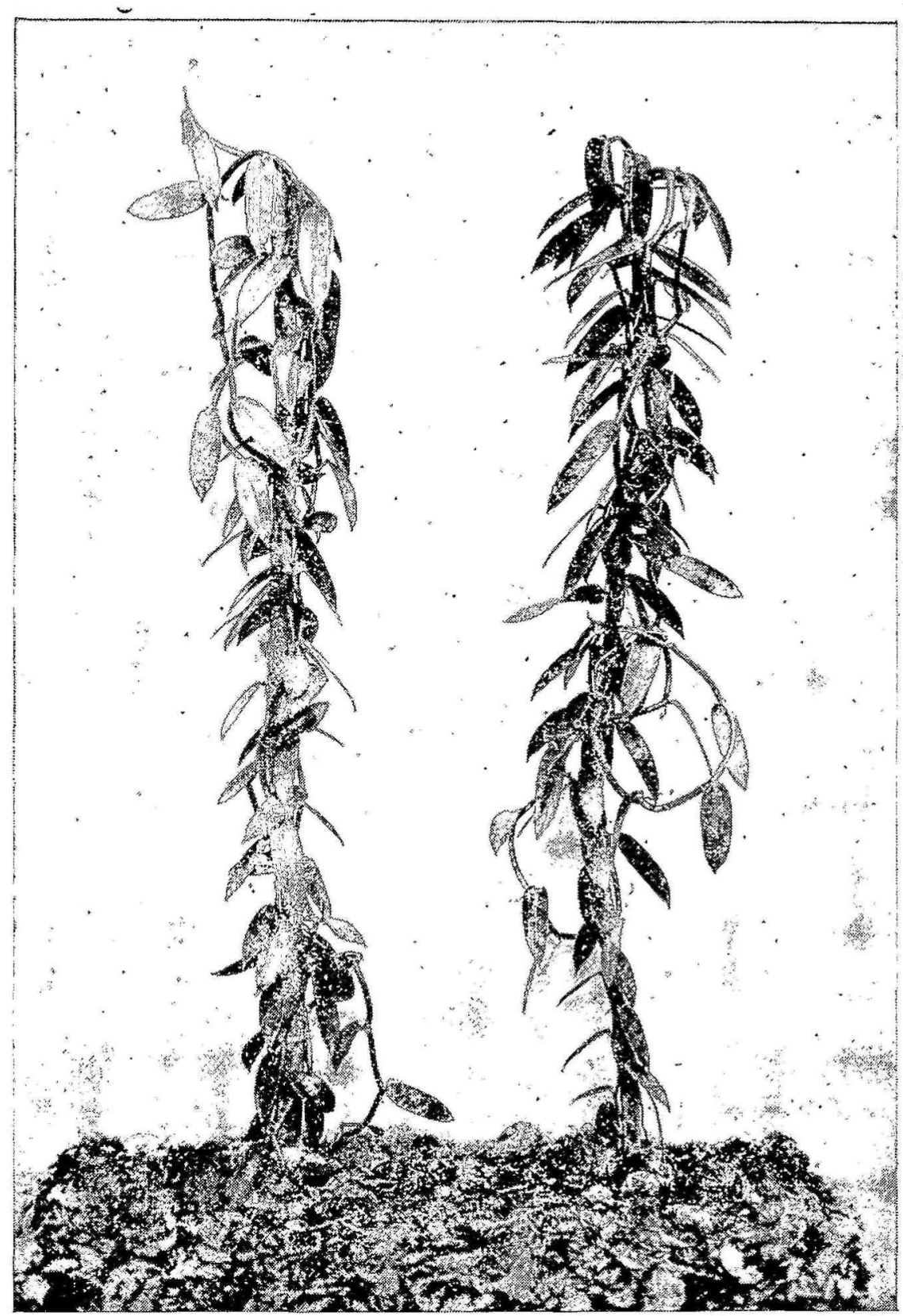

Figure 2. Trypical plants of Vanilla fragrans grown under one-third suntight at the end of 15 months. Note the vigorous condition of the vines and the thick and long internodes. The vines were of a rich dark-green color. 


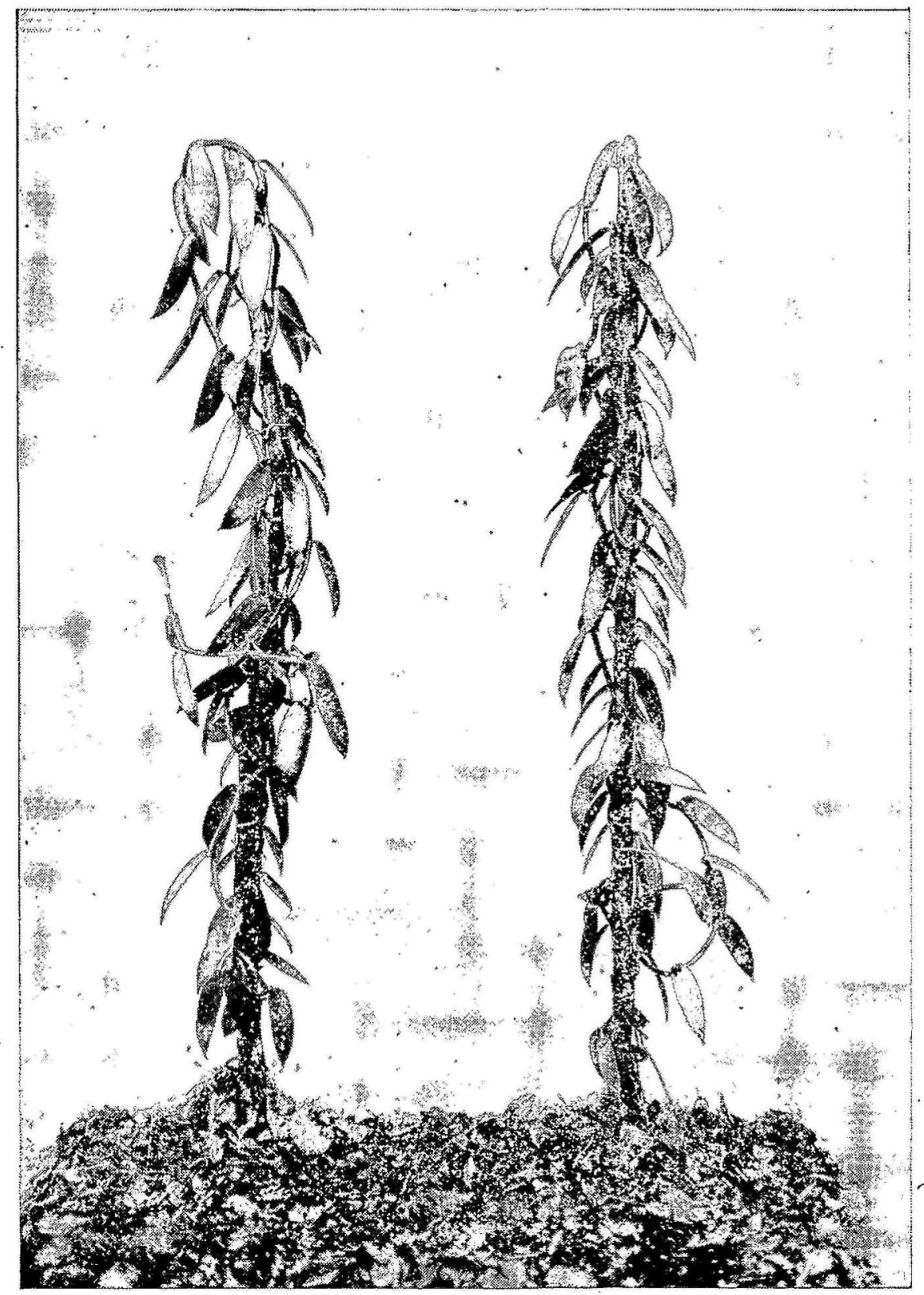

Figure 3. Typical plants of Vanilla fragrans under one-half sunlight at the end of 15 months. The vines were vigorous and had long thick internodes, but the color was somewhat lighter than that of vines exposed to one-third normal sunlight. 


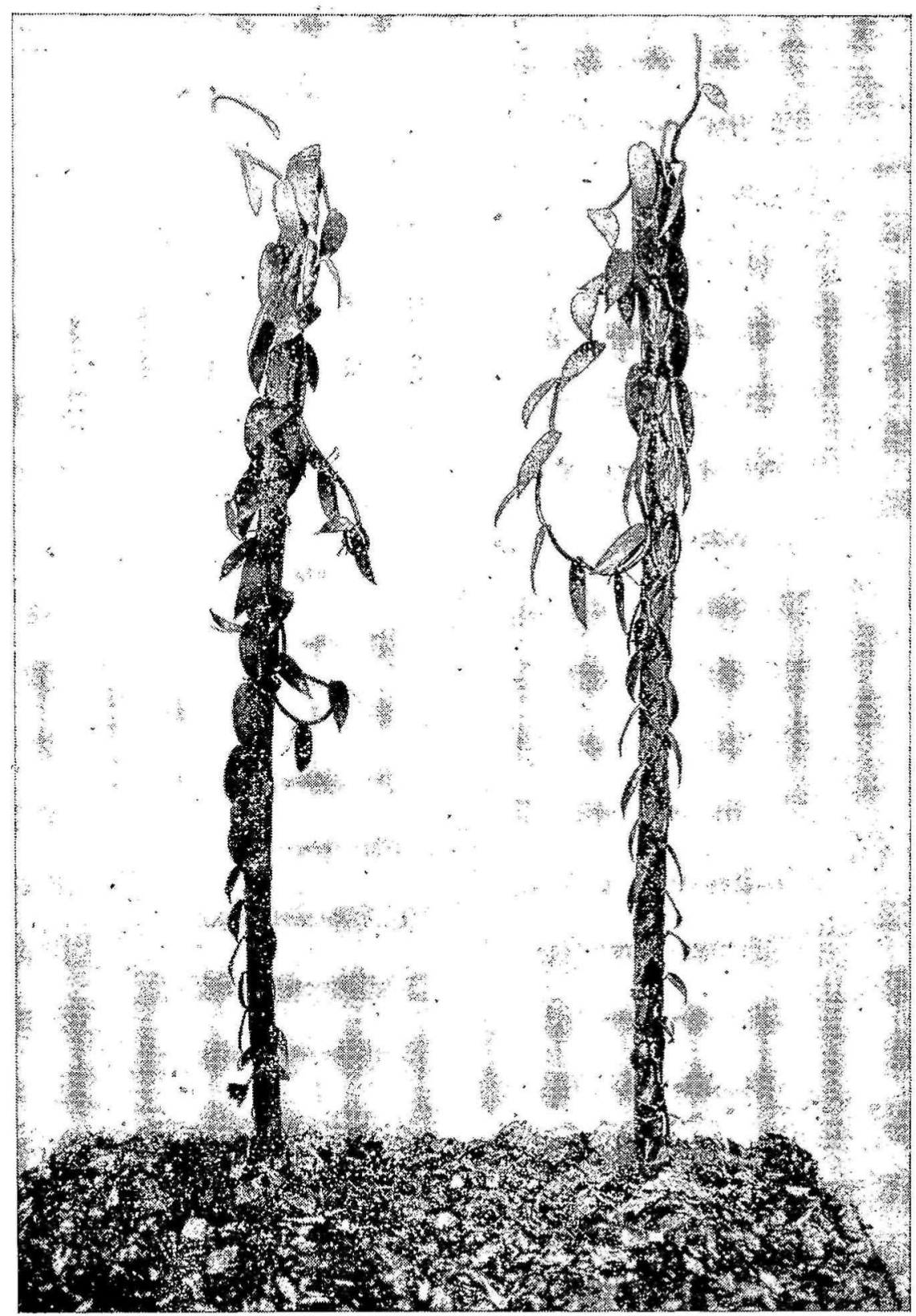

Figure 4. Typical plants of Vanilia fragrans grown under two-thirds suntight at the end of 15 months. These vines were considerably less vigorous than those shown in figures 2 and 3 . Also the internodes were shorter and thinner. The color was yellowish-green. 


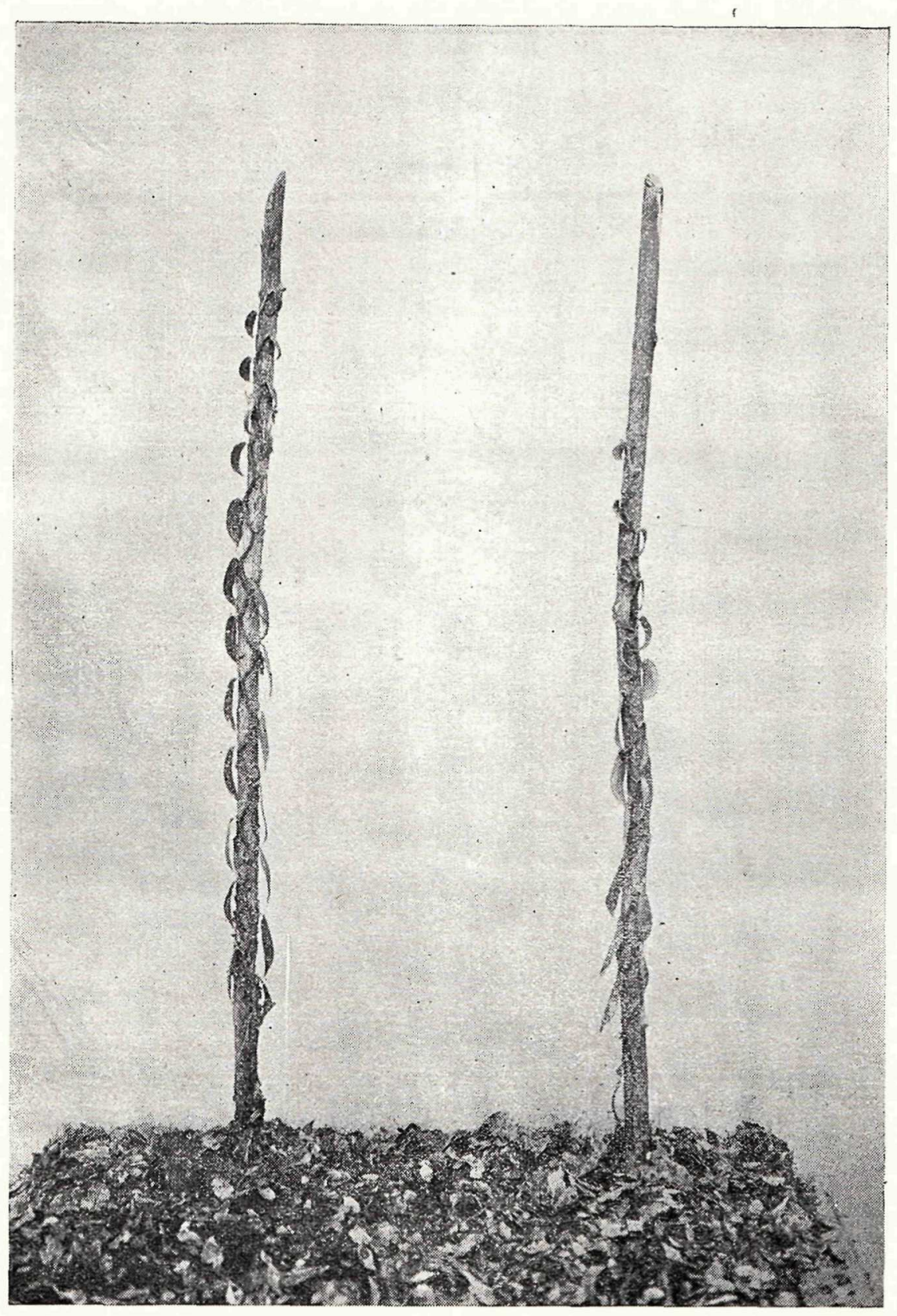

Figure 5. Typical plants of Vanilla fragrans grown under full suntight at the end of 15 months. Note the drooping leaves and short internodes. Vines were yellow-green, almost chlorotic in color. 
standpoint of root germination, seed-piece rotting, and vegetative growth was accomplished under shade conditions which admitted from one-third to one-half the normal sunlight when the sun was directly overhead. The most vigorous and greatest weight of vines and the greatest number of eight-node cuttings were also obtained under those conditions.

\section{S U M A R I O}

Se indica en estudios sobre desarrollo vegetativo que la vainilla requiere abundante sombra. Sembrándose bajo cnatro distintas proporciones de somhra se notó el mejor desarrollo de las plantas cuando se sombreó en tal forma que se admitiera una tercera parte o una mitad de la cantidad de luz solar. riste desarrollo se expresó en producción de raíces, tallo y baja podredumbre de los esquejes. El mejor índice de desarrollo fué el número de esquejes de ocho nudos $y$ la lozanía de las plantas.

\section{LITERATURE CITED}

(1.) Chalot. Ch. and U. Bernard. Establissment d'une vanillerie. (Establishment of a vanillery. In Culture et préparation de la ranille. (Vanilla culture and curing). p. 33-43. 1920.

(2.) Galbraith. S. J. Vanilla culture as practiced in the Sevchelles Islands. U. S. Dept. Agr. Bul. 21: 1-24, pl. 1. fig. 2. 1898.

(3.) MeClelland, T. B. Vanilla: I promising new crop for Porto Rico. Puerto Rico (I. S.) Agr. Exp. Sta. Bul. 26: 1-32, fig. 2. 1919.

(4.) Meinecke. E. P. Les vanillières de Tahiti \& de Moorea. (The vanilleries of Tahiti and Moorea). Report: 1-44. 1916.

(5.) Newport, H. Vanilla culture for tropical Queensland. Queensland Agr. Jour 24: 184-189, pl. 11, fig. 1. 1910. 